\title{
Changes in consumption of milk in Irish children (5-12 years): preliminary analysis from the National Children's Food Survey II
}

\author{
Aileen O’Connor $^{1}$, Maria Buffini ${ }^{1}$, Anne Nugent ${ }^{1,2}$, Laura Kehoe ${ }^{3}$, Janette Walton ${ }^{4}$, \\ John Kearney ${ }^{5}$, Albert Flynn ${ }^{3}$ and Breige McNulty \\ ${ }^{1}$ University College Dublin, Dublin, Ireland, \\ ${ }^{2}$ Queen's University Belfast, Belfast, Ireland, \\ ${ }^{3}$ University College Cork, Cork, Ireland, \\ ${ }^{4}$ Department of Biological Sciences, Cork Institute of Technology, Cork, Ireland and \\ ${ }^{5}$ Technological University Dublin, Dublin, Ireland
}

\begin{abstract}
Introduction: Milk is widely recognised as a nutrient dense food, supporting the growth and development of children. Nevertheless some milk types such as whole milk can consist of high levels of saturated fat, which is recognised for its association with chronic disease risk in adults when intakes are elevated. In Ireland, current dietary guidelines recommend that children from two years onwards should consume low fat milk. Previous research has shown low levels of compliance with this guideline. Therefore the aim of this study is to review the current consumption of milk and non-dairy milk-based alternatives among Irish children and compare these with previous intakes.
\end{abstract}

Materials and methods: Analyses are based on data from the nationally representative National Children's Food Survey (NCFS, 2003-2004) and the National Children's Food Survey II (NCFSII 2017-2018) (www.iuna.net). The NCFS and NCFS II collected detailed food and beverage intake data from 7-d and 4-d weighed food diaries respectively, of Irish children aged 5-12 years (NCFS, n594; NCFS II, n600). Dietary intakes were analysed using WISP ${ }^{\complement}$ in NCFS and Nutritics V5.02 (Nutritics, Dublin, Ireland) in NCFS II. Milk intakes were categorised into three food groups: 'Whole milk', 'reduced fat milk', and 'non-dairy milk

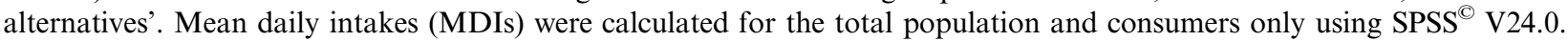

Results: Dietary intakes of 'whole milk' decreased over time from $232 \pm 186 \mathrm{~g} / \mathrm{d}$ to current intakes of $131 \pm 154 \mathrm{~g} / \mathrm{d}$. In contrast, increases were noted in 'reduced fat milks' $(26 \pm 86 \mathrm{~g} / \mathrm{d}$ to $52 \pm 110 \mathrm{~g} / \mathrm{d})$ and 'non-dairy alternatives' $(0.2 \pm 4 \mathrm{~g} / \mathrm{d}$ to $3 \pm 19 \mathrm{~g} / \mathrm{d})$. A total of $68 \%$ of children were classified as consumers of whole milk $(193 \pm 151 \mathrm{~g} / \mathrm{d})$ compared to $90 \%(257 \pm 178 \mathrm{~g} / \mathrm{d})$ previously. 'Reduced fat milk' consumers increased from $17 \%$ to $31 \%$ and 'non-dairy alternatives' consumers also increased from < $1 \%$ to $3 \%$.

Conclusion: Our preliminary results indicate that the number of Irish children consuming whole milk have decreased over the last number of years. In contrast consumers of 'reduced fat milks' have significantly increased, indicating potential improvement to healthy eating guidelines adherence. Further analysis to examine current intakes and sources of saturated fat is warranted to establish additional changes in dietary patterns and compliance with recommendations within this age group.

\section{Conflict of Interest}

There is no conflict of interest 